\title{
Eclampsia: maternal and perinatal outcome among tribal population of Bastar, Chhattisgarh, India in a tertiary care centre
}

\author{
Indu Sharma*, Alpana Bansal
}

Department of Obstetrics and Gynecology, Late BRKM Government Medical College, Bastar, Chhattisgarh, India

Received: 02 April 2016

Accepted: 07 May 2016

\section{*Correspondence:}

Dr. Indu Sharma,

E-mail: georgian.indu@gmail.com

Copyright: (C) the author(s), publisher and licensee Medip Academy. This is an open-access article distributed under the terms of the Creative Commons Attribution Non-Commercial License, which permits unrestricted non-commercial use, distribution, and reproduction in any medium, provided the original work is properly cited.

\section{ABSTRACT}

Background: Eclampsia is one of the major causes of maternal and perinatal morbidity and mortality in India and other developing countries. This problem is continued in spite of challenging efforts to reviev each and every pregnant woman with eclampsia and to analyse the factors affecting the outcome. The aim of the research is to study the demographic profile, maternal as well as perinatal outcome of patients with eclampsia and factor affecting it in tertiary care centre of tribal population.

Methods: A prospective observational and analytical study was conducted over a period of 1.5 years from 1/12/2013 to $1 / 06 / 2015$ in the OBGY department of Govt. Medical College and Associated Maharani Hospital, Bastar, Chhattisgarh, India. All the patients of eclampsia or developed eclampsia admitted in the department were included in the study. Data was collected and analyzed included various maternal parameters and foetal parameters and pregnancy outcome.

Results: During the study period of 1.5 years, incidence of eclampsia among rural and tribal population of Bastar was $4.76 \%$. Among 250 cases of eclampsia, total 28 maternal deaths were there, showing high case fatality rate of $11.2 \%$. 2 maternal deaths were antenatal. Most common cause of maternal death was postpartum haemorrhage $(21.4 \%)$ and pulmonary oedema $(21.4 \%)$. In spite of high case fatality rate, these eclamptic cases developed various complications. One of the factors contributing in poor maternal outcome and developing maternal complication was delay in delivery time from the time of onset of convulsion. Among the cases delivered early ( $<6 \mathrm{hrs}$ ), only $11.4 \%$ cases developed some form of complication whereas among the cases delivered after $24 \mathrm{hrs}$ of onset of convulsion, $74.1 \%$ cases developed complications. Data of study showed poor perinatal outcome as well. $70 \%$ delivery was preterm, $62.4 \%$ live birth, $34.4 \%$ IUD and $4.4 \%$ early neonatal deaths giving $42 \%$ of very high perinatal mortality rate. Most common cause of high perinatal mortality and poor perinatal outcome was prematurity (54.5\%) and meconium aspiration. Most common mode of delivery was vaginal delivery $(82 \%)$ which was associated with more perinatal complication $(47.3 \%)$. In our study most of the cases $(60.4 \%)$ were of very young age (15-24 years) primi gravid $(78.8 \%)$ and unbooked /referred (76.8\%). Majority of them developed ante partum eclampsia (80.8\%) before 37 weeks of gestation $(70 \%)$.

Conclusions: The incidence of eclampsia in our institute was very high with corresponding very high maternal and perinatal morbidity and mortality which emphasizes the need of education, improvement in health care services and universal antenatal checkup and enhancement in timely referral with improvement in transport facilities.

Keywords: Eclampsia, Case fatality rate, Perinatal mortality rate

\section{INTRODUCTION}

Eclampsia refers to the onset of convulsions in a woman with pre-eclampsia that cannot be attributed to other causes. The convulsions may appear before, during or after the labor. It is a serious manifestation that is associated with increased risk of maternal morbidity \& mortality along with poor perinatal outcome. 
Hypertensive disorders are associated with $2^{\text {nd }}$ most common direct obstetric cause of maternal death worldwide. ${ }^{1}$ It accounts for $11-14 \%$ maternal deaths worldwide most of which occur in developing countries. ${ }^{1}$ The incidence of eclampsia varies from place to place as it depends on adequacy of health care to the pregnant women. The incidence is much higher in India and other developing countries ranges from 1 in 100 to 1 in 1700 pregnancies, where as in developed countries it is 1 in 2000 to 1 in 3448 pregnancies. $^{2-5}$ Perinatal mortality is reported to be $5 \%-11 \%$ in developed countries where as it is as high as $40 \%$ in developing countries. ${ }^{6,7}$ According to recent studies due to ignorance regarding antenatal check-up, lack of transport and lack of early communication with tertiary hospital, play an important role in perinatal morbidity and mortality of eclampsia cases.

The present study is undertaken to evaluate the pregnancy outcome in eclampsia patients and to assess maternal and foetal complications in a tertiary care centre of Bastar, a tribal area.

\section{METHODS}

The present study was done in the Department of Obstetrics and Gynecology of Government Medical College and Associated Maharani Hospital, Jagdalpur, Chhattisgarh over a period of 1.5 years from $1^{\text {st }}$ December 2013 to $1^{\text {st }}$ June 2015 . It was hospital based prospective observational analytical study.

\section{Inclusion criteria}

- All antenatal cases with 28 wks or more with h/o convulsions.

- Antepartum, intrapartum and early postpartum cases ( $<7$ days) with h/o convulsions.

\section{Exclusion criteria}

Pregnancy $<28$ wks and postnatal cases >7days, H/o trauma, seizure disorders, brain tumour, cerebral malaria, meningitis, encephalitis and essential HTN (Renal parenchymal disorder).

Patients fulfilling the inclusion criteria were included by taking detail $\mathrm{h} / \mathrm{o}$ present pregnancy, thorough clinical examination, h/o previous pregnancy, h/o associated medical or surgical conditions, lab parameters, outcome of pregnancy, mode of delivery, maternal outcome and fetal outcome.

\section{RESULTS}

In our study period of 1.5 years total 5246 cases were admitted in the OBGY department of Maharani Hospital for their delivery. Among those admitted cases 250 patients were of eclampsia cases. Thus the hospital incidence was $4.76 \%$. Demographic variables of the study showed that eclampsia is most common among unbooked cases $(44.8 \%)$ of early reproductive age $<25$ years $(60.4 \%)$ followed by $25-29$ years(31.6\%) of primigravida(78.8\%) during 33-37 wks of gestation (38\%) followed by $28-32$ wks of gestation (32\%). Commonly convulsions occurred during ante partum period $(80.8 \%)$ and during labor $(18.2 \%)$ than during their postpartum period $(6 \%)$. Most of the eclampsia cases showed high grade of proteinuria i.e. $65.3 \%$ cases have $3+$ and $26.8 \%$ cases have $4+$ proteinuria. Most of the eclampsia cases were delivered vaginaly ( $82 \%$ normal vaginal delivery) whether by applying forceps $(6.4 \%)$ or ventouse $(4.0 \%)$ than caesarean $(7.6 \%)$.

Table 1: Demographic data associated with study.

\begin{tabular}{|lcl|}
\hline Age in Years & $\mathrm{N}(250)$ & $\%$ \\
\hline $15-19$ & 14 & 5.6 \\
\hline $20-24$ & 137 & 54.8 \\
\hline $25-29$ & 79 & 31.6 \\
\hline $30-35$ & 14 & 5.6 \\
\hline$>35$ & 6 & 2.4 \\
\hline Booked/Unbooked & $\mathrm{N}(250)$ & $\%$ \\
\hline Booked & 58 & 23.2 \\
\hline Unbooked & 112 & 44.8 \\
\hline Referred & 80 & 32 \\
\hline Obstetric history & $\mathrm{N}(250)$ & $\%$ \\
\hline G1 & 197 & 78.8 \\
\hline G2-G3 & 43 & 17.2 \\
\hline G4-G5 or $>5$ & 10 & 4.0 \\
\hline Gestational age & $\mathrm{N}(250)$ & $\%$ \\
\hline $28-32$ wks & 80 & 32 \\
\hline $33-37$ wks & 95 & 38 \\
\hline$>37$ wks & 75 & 30 \\
\hline Types of eclampsia & $\mathrm{N}(250)$ & $\%$ \\
\hline Ante partum & 202 & 80.8 \\
\hline Intra partum & 33 & 13.2 \\
\hline Post-partum & 15 & 6.0 \\
\hline Urine albumin & $\mathrm{N}(250)$ & $\%$ \\
\hline $1+$ & 7 & 2.8 \\
\hline $2+$ & 10 & 4.0 \\
\hline $3+$ & 67 & 65.2 \\
\hline $4+$ & 26.8 \\
\hline Absent & 163 \\
\hline & & \\
\hline & & 1.2 \\
\hline
\end{tabular}

In the present study, eclampsia cases developed various complications e.g. ante partum haemorrhage, postpartum haemorrhage, HELLP Syndrome, DIC, ARF, Retinopathy, CVA, pulmonary oedema, CCF, coma, sepsis, and maternal mortality. Among these complications, ante partum haemorrhage (6.8\%), postpartum haemorrhage (8.4\%), ARF (13.2\%), HELLP syndrome $(4.4 \%)$, pulmonary oedema (4.4\%) and septicaemia $(2.8 \%)$ were most common cause of maternal morbidity in eclampsia cases. Maternal mortality occurred in 28 cases $(n=250$ i.e. $11.2 \%)$. Case fatality rate was $11.2 \%$. Common causes of maternal mortality were 
CVA (17.8\%), pulmonary oedema (21.4\%), HELLP (14.28\%), sepsis $(10.7 \%)$, ARF $(17.8 \%)$ and postpartum haemorrhage $(10.7 \%)$. Most of the maternal complications $(74.1 \%, 23 / 31)$ were associated with delay in delivery from onset of convulsion (>24 hrs) whereas comparatively very few complications were seen among eclamptic cases delivered within $6 \mathrm{hrs}$ of onset of convulsion $(10.6 \%, 7 / 66)$. Only 4 cases of post-partum eclampsia (4/15) were complicated. Among 28 maternal deaths 2 eclampsia patients died antenataly.

Table 2: Maternal complications.

\begin{tabular}{|lll|}
\hline Maternal complication & Cases $(\mathbf{n}=\mathbf{2 5 0})$ & $\%$ \\
\hline APH(abruptio) & 17 & 6.8 \\
\hline HELLP & 11 & 4.4 \\
\hline DIC & 5 & 2.0 \\
\hline ARF & 33 & 13.2 \\
\hline Retinopathy & 14 & 5.6 \\
\hline CVA & 6 & 2.4 \\
\hline Pulmonary oedema & 11 & 4.4 \\
\hline CCF & 4 & 1.6 \\
\hline PPH & 21 & 8.4 \\
\hline Coma & 3 & 1.2 \\
\hline Sepsis & 7 & 2.8 \\
\hline Mortality & 28 & 11.2 \\
\hline BT & 26 & 10.4 \\
\hline
\end{tabular}

Table 3: Association of onset of convulsion to delivery interval with maternal outcome.

\begin{tabular}{|llll|}
$\begin{array}{l}\text { Convulsion } \\
\text { to delivery } \\
\text { interval }\end{array}$ & $\begin{array}{l}\text { No. of } \\
\text { patients }\end{array}$ & $\begin{array}{l}\text { Maternal } \\
\text { complication }\end{array}$ & $\%$ \\
\hline$<6 \mathrm{hr}$ & 61 & 7 & 11.4 \\
\hline $6-12 \mathrm{hr}$ & 84 & 21 & 25.0 \\
\hline $12-24 \mathrm{hr}$ & 59 & 29 & 49.1 \\
\hline$>24 \mathrm{hr}$ & 31 & 23 & 74.1 \\
\hline
\end{tabular}

Table 4: Maternal mortality.

\begin{tabular}{|lll|}
\hline Causes & Cases $(\mathbf{n = 2 8})$ & $\%$ \\
\hline CVA & 5 & 17.8 \\
\hline Pulmonary oedema & 6 & 21.4 \\
\hline HELLP & 4 & 14.28 \\
\hline Sepsis & 3 & 10.7 \\
\hline PPH & 3 & 10.7 \\
\hline ARF & 5 & 17.8 \\
\hline MOD & 2 & 7.1 \\
\hline Case fatality rate & $28 / 250$ & 11.2 \\
\hline
\end{tabular}

In the present study, data showed $62.4 \%$ live births (156/250), 34.4\% IUD (86/250) and 3.2\% still birth (8/250). Most of them were preterm (70\% i.e.175/250). Out of those live births (156), neonatal deaths were $11(7.0 \%)$ mostly because of prematurity $(6 / 11,54.5 \%)$ and meconeium aspiration syndrome $(3 / 11,27.2 \%)$. The perinatal mortality rate of the study was $42 \%$. Although the most common mode of delivery was vaginal delivery $(82 \%)$ but vaginal route is associated with poor perinatal outcome. Most of the foetus as well as neonates (97/205, $47.3 \%$ ) developing complications were associated with vaginal delivery whereas only $5.2 \%$ (1/19) perinatal complications were associated with caesarean delivery. There were 2 sets of twin delivery.

Table 5: Perinatal outcome.

\begin{tabular}{|lll|}
\hline Perinatal outcome & Cases $(\mathbf{n = 2 5 0})$ & $\%$ \\
\hline Term(>37wks) & 75 & 30 \\
\hline Preterm & 175 & 70 \\
\hline Live Birth & 156 & 62.4 \\
\hline Still Birth & 8 & 3.2 \\
\hline IUD & 86 & 34.4 \\
\hline Neonatal death & 11 & 4.4 \\
\hline Low APGAR $(<7)$ & 35 & 14 \\
\hline IUGR & 45 & 18 \\
\hline
\end{tabular}

Table 6: Association of mode of delivery with perinatal complications.

\begin{tabular}{|c|c|c|c|}
\hline \multirow{2}{*}{$\begin{array}{l}\text { Mode of } \\
\text { delivery }\end{array}$} & \multirow{2}{*}{$\begin{array}{l}\text { Cases } \\
\text { (n) }\end{array}$} & \multicolumn{2}{|c|}{ Perinatal complication } \\
\hline & & cases & $\%$ \\
\hline NVD & 205 & 97 & 47.3 \\
\hline VACCUM & 16 & 3 & 18.7 \\
\hline FORCEPS & 10 & 3 & 30 \\
\hline LSCS & 19 & 1 & 5.2 \\
\hline
\end{tabular}

Table 7: Causes of neonatal death.

\begin{tabular}{|lll|}
\hline Causes & Cases $(\mathbf{n}=\mathbf{1 1})$ & $\%$ \\
\hline Preterm & 6 & 54.5 \\
\hline Asphyxia & 1 & 9.0 \\
\hline MAS & 3 & 27.2 \\
\hline IUGR & 1 & 9.0 \\
\hline
\end{tabular}

\section{DISCUSSION}

The present study has shown the incidence of eclampsia in a tertiary care centre of Bastar a tribal area of Chhattisgarh to be $4.76 \%$ which is much higher than North India, New Delhi (3.2/1000 deliveries), Uttar Pradesh (2.2\%), Karnataka (2.19/1000 deliveries), West Bengal (3.57\%), and Eastern India (3.2\%). ${ }^{8-11}$ This incidence is higher than other developing countries also. $^{12-15}$ The incidence of eclampsia in developed countries is estimated to about 5-7/10,000 deliveries whereas in developing countries varies widely 1 case/100 to 1 case/1700 pregnancies. ${ }^{5,16,17}$ Majority of the patients are of primigravida $(78.8 \%)$ in their early reproductive age $<25$ years $(60.4 \%)$ with unsupervised pregnancy ( in their antenatal period and referred cases $(76.8 \%)$. These data's are comparable to other studies. ${ }^{8-10,18-20}$ This indicates the lack of education and awareness regarding antenatal care along with absence of good quality of 
health services which is responsible for higher incidence of eclampsia in developing countries than in developed countries. Most probable cause of much higher incidence of eclampsia in our study population is that it is a single tertiary referral centre of large tribal area (around $300 \mathrm{~km}$ draining area), along with illiteracy and poor access to health care facilities. The incidence in developed countries is much lower due to provision of antenatal care to all pregnant women and better access to health care facilities. $^{21,22}$ In our study most of the cases developed ante partum eclampsia $(80.8 \%)$ before 37 weeks of gestation $(70 \%)$ similar to other Indian studies and study conducted in Nigeria by Jido TA, whereas in the UK, $44 \%$ of eclampsia were postpartum and had lower incidence of ante partum eclampsia which could be due to good ANC surveillance..$^{8-10,14,19}$ The present study showed $3+$ and $4+$ urine albumin by dipstick test in most of the eclamptic patients $(65.2 \%$ and $26.8 \%)$ correlating with poor maternal and perinatal outcome..$^{12,19,20}$

In the present study, most of the eclamptic patients (82\%) were delivered by vaginal route similar to other Indian studies due to lack of facilities for intensive care in our institute but in recent years as well as in developed countries caesarean section has been opted for the preferred mode of delivery. , $^{9} 10,12,18-20,23$

In our institute, during study period of 1.5 years, $33.6 \%$ eclamptic (84/250) cases develop some form of complications e.g. PPH (8.4\%), APH (6.8\%), ARF (13.2\%), Hypertensive retinal changes $(5.6 \%)$, pulmonary oedema (4.4\%), HELLP syndrome (4.4\%), DIC (2.0\%), Septicaemia $(2.8 \%)$, prolonged unconsciousness $(1.2 \%)$ and death (11.2\%) similar to study of Pradeep MR et al, Sunita $\mathrm{TH}$ et al and the study conducted in Nigeria but case fatality rate $(11.2 \%)$ is very high in comparison to other Indian studies as well as from developed countries because of being a tribal area there are limited health resources and there is delay in reaching the tertiary care centre as most of the cases (52/84) developing complications having large interval ( $>12 \mathrm{hrs}$ ) from onset of convulsion to delivery which is a significant factor determining the maternal as well as perinatal outcome. ${ }^{5,8-}$ 10,12,18,19,23-25 Most common cause of maternal death in our study is pulmonary oedema $(21.4 \%)$ because of limited facility of intensive care unit, ventilator as well as large drainage area of poor tribal population. Other deaths are due to HELLP syndrome, ARF, Septicaemia, Cerebral haemorrhage and multiorgan failure.

The present study shows perinatal mortality rate of $420 / 1000$ live births which is very high in comparison to the study of Aparna Khan et al, Sunita TH et, Pannu D et al and from developed countries and comparable with the study of Rajasri G et al and Pradeep MR et al. ${ }^{8-10,12,19,20,25}$ Most common cause of high perinatal mortality is prematurity $(54.5 \%)$ followed by meconeium aspiration syndrome $(27.2 \%){ }^{8,13,19}$ Similar to other studies our study also correlate poor perinatal outcome with vaginal delivery. ${ }^{19,20}$ In the developed countries where C-section is preferred mode of delivery for salvageable babies even if estimated foetal weight is low, have good perinatal outcome. ${ }^{12,23,26}$ Our conservative attitude towards vaginal delivery has affected the perinatal outcome badly.

Eclampsia continues to be an important cause of maternal and perinatal morbidity mortality. As the data of present study shows higher incidence, among early reproductive age group of primigravida of tribal population of Bastar than other Indian studies conducted in other regions of the country, with higher perinatal and maternal complications as well as deaths reflects poverty, illiteracy, lack of awareness regarding health services, poor antenatal care and limited health resources. One of the major contributors of poor outcome is delayed referral and delayed presentation with complication to our institute which is in itself a single tertiary care centre draining large population and has lack of intensive care services for mother as well as for neonates. Eclampsia is a preventable challenge which can be dealt by improving the basic health care provided to all pregnant women as well as educating them so that high risk women could be recognized early for timely intervention before landing up into complications.

\section{ACKNOWLEDGEMENTS}

I would like to thank faculty and staff of my department and Maharani Hospital specially my HOD, Dr Prabha Chauhan, for their substantial contributions. I would also like to thank all the study participants.

Funding: No funding sources

Conflict of interest: None declared

Ethical approval: Not required

\section{REFERENCES}

1. Global causes of maternal death: a WHO systematic analysis. Say L, Chou D, Gemmill A, Tunçalp O, Moller A, Daniels J. http://www.thelancet.com/ lancetgh Vol 2 June 2014

2. World Health Organization. Global Program to Conquer Preeclampsia/ Eclampsia. 2002.

3. WHO. Coverage of Maternity Care: A Listing of Available Information. Geneva, Switzerland: World Health Organization; 2004.

4. Andersgaard AB, Herbst A, Johansen M. Eclampsia in Scandinavia: incidence, substandard care, and potentially preventable cases. Acta Obstet Gynecol Scand. 2006;85(8):929-36.

5. Fong A, Chau CT, Pan D. Clinical morbidities, trends, and demographics of eclampsia: a populationbased study. Am J Obstet Gynecol. 2013;209(3):229.e1-7.

6. Knight M. Eclampsia in the United Kingdom 2005. BJOG. 2007;114(9):1072-8.

7. Onuh SO, Aisien AO. Maternal and fetaloutcome in eclamptic patients in Benin City, Nigeria. J Obstet Gynaecol. 2004;24(7):765-8 
8. Pannu D, Das B, Hazari P. Maternal and perinatal outcome in eclampsia and factors affecting the outcome: a study in North Indian population. Int $\mathrm{J}$ Reprod Contracept Obstet Gynecol. 2014;3(2):34751.

9. Pradeep MR, Shivanna L. Retrospective Study of Eclampsia in a Teaching Hospital. Int Journal of Recent Trends in Science and Technology. 2013;8(3):171-3.

10. Khan A, Ghosh A, Banerjee PK. Profile and Outcome of Eclampsia in a Rural Tertiary Hospital, Int. J. of Recent Trends in Science and Tech. 2014;10(3):526-9.

11. Singh S, Behera AK. Eclampsia in Eastern India: incidence, demographic profile and response to three different anticonvulsant regimes of magnesium sulphate. Internet J Gynecol Obstet. 2011;15(2):1-8

12. Adekanle DA, Akinbile TO. Eclampsia and Pregnancy Outcome at Lautech Teaching Hospital, Osogbo, South West, Nigeria, Clinics in Mother and Child Health. 2012;9, Article ID C120301,4 pages.

13. Abdullah A, Shaikh AA, Jamro B. Maternal and perinatal outcome associated with eclampsia in a teaching hospital, sukkur. RMJ. 2010;35(1):23-6.

14. Jido TA. Ecalmpsia: maternal and fetal outcome, African Health Sciences. 2012;12(2):148-52.

15. Ndaboine EM, Rumanyika R. Maternal and perinatal outcomes among eclamptic patients admitted to Bugando medical centre, Mwanza, Tanzania. Afr J Reprod Health. 2012;16(1):35.

16. World Health Organization. Global Program to Conquer Preeclampsia/ Eclampsia. 2002.

17. WHO. Coverage of Maternity Care: A Listing of Available Information. Geneva, Switzerland: World Health Organization; 2004.
18. Kumar S, Bansal D, Hota D. Assessment of clinical outcomes and prescribing behavior among inpatients with severe preeclampsia and eclampsia: An Indian experience. Indian J Pharmacol. 2014;46(1):18-23.

19. Sunita TH, Desai RM. Eclampsia in a Teaching Hospital: Incidence, clinical profile and response to Magnesium Sulphate by Zuspan's regimen, IOSR Journal of Dental and Medical Sciences. 2013;4(2):1-5.

20. YaliWal RG. Eclampsia and Perinatal Outcome: A Retrospective Study in a Teaching Hospital, Journal of Clinical and Diagnostic Research. 2011;5(5):1056-9.

21. Lal AK, Gao W. Eclampsia. Maternal and neonatal outcomes. Pregnancy hypertension. Int JWomen's Cardiovas Health. 2013;3:186-90.

22. Zwart J, Richters A, Ory F, Vries J, Roosmalen J. Eclampsia in the Netherlands. Obstet Gynaecol. 2008;112:820-7.

23. Jumaida AB, Mukudan K, Karalasingam SD, Ravichandran J, Ravidran JR, Soelar SA. Maternal and Fetal Outcomes among Eclamptic Patient at Tertiary Hospitals in Malayasia. Clinical Research Centre, Kualalampur, 2013.

24. Sarkar M, Basak S, MD, Das S, Roy MS, Mandal J. Maternal mortality associated with eclampsia in an Indian medical college: a four year retrospective study, Journal of Medicine and Medical Sciences. 2013;4(10):394-8.

25. Douglas KA, Redman CWG. Eclampsia in the United Kingdom. BMJ. 1994;309:1395-400.

26. Innocent O. George and Israel Jeremiah, Perinatal Outcome of Babies Delivered to Eclamptic Mothers: A Prospective Study from a Nigerian Tertiary Hospital, Int. J Biomed Sci. 2009;5(4):390-4.

Cite this article as: Sharma I, Bansal A. Eclampsia: maternal and perinatal outcome among tribal population of Bastar, Chhattisgarh, India in a tertiary care centre. Int J Reprod Contracept Obstet Gynecol 2016;5:1887-91. 